\title{
Design Considerations for the Batch Capture of Proteins from Raw Whole Milk by Ion Exchange
}

\section{Chromatography}

Conan J. Fee* and Amita Chand

*Corresponding Author

Department of Materials and Process Engineering, University of Waikato, Private Bag 3105, Hamilton 2020, New Zealand. Phone: +64 7838 4206, Fax: +64 8384835.

c.fee@waikato.ac.nz 


\begin{abstract}
Batch extraction of proteins directly from raw, whole milk is described with a focus on design considerations for on-farm implementation. A demonstration of single-stage stirred tank extraction of bovine lactoferrin onto cation exchangers shows that processing can be achieved, with no pre-treatment of raw milk, within the timeframe required to milk an individual animal. The extraction rates of two cation exchange media, SP Sepharose Big Beads $^{\mathrm{TM}}$ and SP Sepharose FFTM (GE Healthcare, Uppsala, Sweden), are compared, with the smaller FF media (average diameter $90 \mu \mathrm{m}$ ) having a faster adsorption rate than the larger BB media (155 $\mu \mathrm{m})$. Maximum percentages of original protein extracted by SP Sepharose FF were $67 \%, 80 \%, 88 \%$ and $90 \%$ for extraction times of 5, 10, 20 and 30 minutes, respectively. The composite nonlinear kinetic model of Rowe et al [1] was found to fit the batch adsorption of LF from raw milk as a function of chromatography media volume to milk volume ratio, $\Phi$. At extraction times of 30 minutes and longer, extraction \% was almost independent of $\Phi$ over the range of values tested.
\end{abstract}

On-farm extraction of proteins shows promise for both the production of minor, high-value proteins from conventional milk and for production of recombinant proteins from the milk of transgenic animals. The main advantage of the stirred tank process is that protein extraction is rapid and is achieved in a single step without the need for pre-treatment of milk. The process is not limited to ion exchange but could be implemented using other chromatographic techniques, such as affinity or reverse-phase chromatography. 


\section{Introduction}

Over the past two decades, the dairy industry globally has moved from being based solely on commodity food production to earning a significant income from specialty proteins. Two examples are lactoferrin and lactoperoxidase, which can be isolated from skim milk or cheese whey by cation exchange because of their high isoelectric points compared to the other major whey proteins, $\alpha$-lactalbumin, $\beta$-lactoglobulin, bovine serum albumin and immunoglobulins, e.g. [2]. Another need for fractionation of milk proteins arises from the production of recombinant proteins from the milk of transgenic animals [3-15]. Typical concentrations, molecular weights and isoelectric points of whey proteins are given in Table $1[16]$.

Pre-treatment of milk prior to chromatographic capture of proteins is virtually universal [1739]. In a review of downstream processing of recombinant proteins from transgenic feedstock, Nikolov and Woodard [13] identified the removal of fat globules and casein micelles from milk by centrifugation, acid precipitation, and/or membrane filtration as being critical for reducing fouling in subsequent purification steps.

Four recent examples of typical pre-treatments in laboratory studies that are intended to be relevant to industrial processes are described briefly here by way of example. Hahn et al [34] first centrifuged milk at $4,420 \mathrm{~g}$ for 30 minutes to remove fat, then acidified to precipitate casein and centrifuged at 17,700 g for 30 minutes, diluted with distilled water and finally filtered through $0.45 \mu \mathrm{m}$ filter before applying whey to a cation exchange chromatography column. Doultani et al [39] adjusted the $\mathrm{pH}$ of mozzarella cheese whey with $\mathrm{H}_{2} \mathrm{SO}_{4}$ and passed it through Whatman No. 5 filter paper before applying it to their cation exchange column. Ye et al [38] used both anion and cation exchange chromatography to isolate $\alpha-$ lactalbumin, $\beta$-lactoglobulin, lactoferrin (LF) and lactoperoxidase (LP) from rennet whey produced from skim milk that had first been defatted by centrifugation. After incubation for one hour with rennet, the caseins were separated by filtration and the whey thus produced was then centrifuged at 10,000 g for 25 minutes before applying it to the column. Lyndsay et al [12], purifying recombinant DNA-derived factor IX from the milk of transgenic pigs, used EDTA to dissolve casein micelles, followed by centrifugation to remove fat and 5-fold dilution in heparin loading buffer prior to loading onto a heparin-Sepharose FF column. 
Proteins should be separated from a source material as fast and in as few steps as possible to avoid loss of activity and yield [40, 41]. Losses due to individual steps and complex separation sequences can be severe. For example, Nuyens and Vav Veen [42] reported that acid precipitation of casein resulted in $4-8$ times more LF entrapped in the casein pellet than in the whey fraction and Denman et al [3] lost 50\% of human tissue-type activator produced in transgenic goats milk in the acid precipitation step, and obtained just a $25 \%$ overall yield.

The concept of capture of high-value proteins from raw whole milk on the farm directly after milking has been patented [43] and would better fit with the accepted principles of bioseparation process design i.e. fast processing with a minimum of steps. Such a process would need to be fast, simple and avoid the extensive pre-treatments described above.

A typical bovine milk contains $13 \%$ solids, with $4 \%$ fat present as an emulsion of globules with diameters up to $10 \mu \mathrm{m}$ and caseins present as a colloidal suspension of particles with diameters up to $0.1 \mu \mathrm{m}$ [44]. Fat globules cause problems for chromatographic separations, as they block packed columns as soon as the feed is introduced. Therefore, fat is usually removed prior to cation exchange capture of LF and LP from skim milk. The authors have shown, in related work [45], that there is no need to remove fat globules or casein micelles prior to extracting LF and LP from raw, whole milk using a packed bed of SP Sepharose Big Beads $^{\text {TM }}$ (GE Healthcare, Uppsala, Sweden), provided that the processing temperature is sufficiently high. More than 100 column volumes of raw, untreated milk at $35{ }^{\circ} \mathrm{C}$ could be passed through a $5 \mathrm{~cm}$ height packed bed at $300 \mathrm{~cm} / \mathrm{hr}$ without exceeding the maximum backpressure of the media $(0.3 \mathrm{MPa})$, and a dynamic media loading capacity of approximately $48.6 \mathrm{mg} / \mathrm{mL}$ was achieved.

Milk is normally processed at $4-10{ }^{\circ} \mathrm{C}$ because of the need to minimise bacterial growth during long holding periods and multiple process steps in the factory. At these temperatures, milk fat hardens or solidifies, causing blockage of chromatography columns. Oleic acid makes up 30 to $40 \%$ of the total fatty acids in milk [44] and its melting point $\left(14{ }^{\circ} \mathrm{C}\right)$ corresponds well with the temperature below which milk no longer passes through the bed 
[45]. At higher temperatures, oleic acid presumably softens milk fat globules, allowing them to deform and pass through the inter-particle voids.

If proteins can be extracted quickly by chromatography immediately after milking, microbial growth may not be a factor. Milk intended for further processing can easily be cooled after only a slight delay as it exits the chromatography column, while on-processing (and therefore bacterial count) of transgenic milk is not an issue once the target protein has been extracted.

The purpose of this study was to explore design parameters for the batch extraction of proteins directly from un-treated, raw, whole milk by ion exchange chromatography. For reasons described below, a single-stage stirred tank batch system was chosen. LF was chosen as a model protein, as it could be extracted (along with LP) using cation exchange without interference from the major milk proteins. SP Sepharose Big Beads ${ }^{\mathrm{TM}}$ (BB) (GE Healthcare, Uppsala, Sweden) were chosen initially because it has US Food and Drug Administration approval for food use (CAS Reg. No. 676618-71-6, FDA notification FCN 000443 ) [46]. A series of experiments were carried out to assess the kinetics of LF adsorption on BB and SP Sepharose FFTM (FF) cation exchange media (GE Healthcare, Uppsala, Sweden) and to determine the effects of processing parameters on yield. 


\section{Design Considerations}

Our objective was to incorporate a chromatographic extraction unit into an existing automated milking system (AMS) [47] and extract proteins on-farm, directly from raw, untreated milk, immediately after each individual milking [43]. Our success with raw milk flow through a packed column of $\mathrm{BB}$ media at $35^{\circ} \mathrm{C}$ (nominal temperature) indicated that a column $5 \mathrm{~cm}$ high by $36 \mathrm{~cm}$ diameter, could cope with extraction of virtually $100 \%$ of the LP and 95\% of the LF from 33 cows [45]. Therefore we initially envisaged an appropriate number of such columns or one larger column to cope with the number of individual milkings per day per AMS.

However, the problem of microbial growth would become an issue for a column repeatedly loaded with raw milk and maintained at $35{ }^{\circ} \mathrm{C}$ over the course of many hours. Such an arrangement would require column cleaning and sanitation between milkings. The adsorbed protein is unlikely to withstand prolonged storage at warm temperatures or repeated cleaning. Both aspects could be dealt with by eluting the protein between milkings but in this case the column should be sized appropriately for a single milking.

We can explore the approximate design dimensions of such a packed-bed column with the above information plus our observation that an average milk volume from the AMS per milking is approximately $15 \mathrm{~L}$. The total LF and LP in $15 \mathrm{~L}$ of milk is approximately $8 \mathrm{~g}$ and the dynamic media capacity is approximately $50 \mathrm{mg} / \mathrm{mL}$, so about $150 \mathrm{~mL}$ of media is required per milking. If we set the total processing time arbitrarily to 3 minutes per milking to minimise the time the milk spends at $35{ }^{\circ} \mathrm{C}$, and the linear flow rate to $300 \mathrm{~cm} / \mathrm{hr}$, then the diameter of the bed is fixed at $36 \mathrm{~cm} .150 \mathrm{~mL}$ of media corresponds to a bed height of only $1.5 \mathrm{~mm}$, which is clearly not practical. Reducing the column diameter to increase bed height would result in either correspondingly faster linear flow rates (which would reduce dynamic capacity and cause faster column blockage [45]) or longer processing times (which would increase microbial growth and is constrained by the need to fit the process within the normal time taken to milk an individual cow).

Figure 1 shows the effect column diameter has on the three design parameters, bed height, time required for processing at $300 \mathrm{~cm} / \mathrm{hr}$ and the flow rate required to process in 3 minutes. Bed height does not reach a practical (though still very small) value $(2 \mathrm{~cm})$ until column 
diameter is reduced to $10 \mathrm{~cm}$ but at this point the time required to process $15 \mathrm{~L}$ of milk approaches 40 minutes. Alternatively, at this diameter the flow rate would need to be almost $4000 \mathrm{~cm} / \mathrm{hr}$ to complete processing in 3 minutes.

These design constraints suggest that a packed-bed column may not be the best approach to capture of proteins from individual cows.

Another design consideration is that an AMS can identify each individual animal through, for example, use of radio frequency identification (RFID) tags, can control milking events, collect milking data for each animal, interface with on-line sensors and control ancillary equipment. This raises the possibility of linking an adsorption device to an AMS to optimise extraction from each animal. Data on final product yield and activity for individual animals, coupled with information gathered from the AMS, would give the farmer the ability to identify high-producing animals from the herd and to relate various farm management practices (milking frequency and time, feeding regimes, etc) to productivity of specific protein targets rather than gross measures of total milk volume or milk solids.

Finally, the regulatory process for production of recombinant proteins intended for human therapeutic use from the milk of transgenic animals may be more readily satisfied if the protein could be traced back to each individual animal throughout the production process. For example, if an animal developed signs of ill-health or infection, batch traceability would allow product originating from that specific animal to be withdrawn for further testing or disposal. Likewise, problems with individual product lots picked up during the QA process could be traced back to the individual animal rather than the whole herd.

The above considerations led us to investigate protein adsorption from individual animals using a single-stage stirred tank. Straining is the simplest method to recover the ion exchange media in a compact volume after adsorption. The need to retain flow through the bed as it builds up on the strainer mesh means that the milk should be maintained at or near the temperature at which it comes out of the cow. Adsorption kinetics, which should ideally be fast enough to fit within the time taken to milk each animal, would also be higher at this temperature than if the milk were cooled. 


\section{Materials and Methods}

Raw milk was obtained from the Greenfield dairy farm site (Dexcel Limited and Sensortec Limited, New Zealand), from cows milked using an automated milking system. Milk was held after collection at 35 to $37{ }^{\circ} \mathrm{C}$ with gentle stirring to prevent fat separating under the influence of gravity.

Chemicals were obtained from BDH Chemicals (Poole, England) unless otherwise specified. Bovine lactoferrin standards were obtained from Sigma-Aldrich (St Louis, MO, USA) and Bethyl Laboratories (Montgomery, Texas, USA). Affinity purified goat polyclonal antibovine lactoferrin antibody $(1 \mathrm{mg} / \mathrm{mL})$ was obtained from Bethyl Laboratories and used for both ELISA and surface plasmon resonance (SPR) analysis.

SP Sepharose Big Beads' ${ }^{\mathrm{TM}}$ and SP Sepharose FFTM (GE Healthcare, Uppsala, Sweden) were used to adsorb lactoferrin from untreated milk. Media was equilibrated before use in $10 \mathrm{mM}$ phosphate buffer (10 $\mathrm{mM}$ mono and dibasic sodium phosphate) at $\mathrm{pH}$ 6.7. LF was eluted in the same buffer containing $1.0 \mathrm{M} \mathrm{NaCl}$ in a single step.

To determine equilibrium isotherms, $0.2 \mathrm{~g}$ of equilibrated, swelled, drained media was quantitatively weighed into $10 \mathrm{~mL}$ centrifuge tubes. Lactoferrin from samples of known purity (Tatua Dairy Cooperative Limited, Morrinsville, New Zealand) was constituted to concentrations ranging from 0.05 to $20.0 \mathrm{mg} / \mathrm{mL}$. $5 \mathrm{~mL}$ of each solution was added to the media and left for 24 hours on a rotating plate within an incubator at $37 \pm 0.2{ }^{\circ} \mathrm{C}$. The tubes were then centrifuged to remove the media from suspension and the supernatant was filtered using a $5 \mu \mathrm{m}$ filter. The equilibrium lactoferrin $\left(\mathrm{C}_{\mathrm{LF}}{ }^{*}\right)$ concentrations were determined using the Bincinchoninic acid (BCA) protein assay (Pierce, Rockfield, IL, USA), sensitive between 20 and $1200 \mu \mathrm{g} / \mathrm{mL}$. The amount of protein bound to the media was calculated from the difference between the initial and final solution protein concentration and the equilibrium binding capacity for lactoferrin, $\mathrm{Q}_{\mathrm{LF}}{ }^{*}$, were calculated by dividing the amount bound by the volume of the media.

Extraction rates of lactoferrin from raw milk in stirred tanks were determined for both media as follows. Aliquots of 2.0, 2.5 and $4.8 \mathrm{~mL}$ of swelled, drained media were added to $200 \mathrm{~mL}$ 
of milk in beakers, placed in a water bath at $36 \pm 1{ }^{\circ} \mathrm{C}$. The ratios of media volume to milk volume in these experiments were equivalent to $250 \mathrm{~mL}$ of media added to 25, 20 and 10.4 L milk, respectively. Gentle stirring (150 rpm) was applied using a multi-head stirrer system (Boltac Industries, Hamilton, New Zealand). $1 \mathrm{~mL}$ samples were withdrawn from the milk/media slurry by syringe at timed intervals, passed through a $5 \mu \mathrm{m}$ filter (Sartorious AG, Goettingen, Germany) and analysed for lactoferrin concentration.

Lactoferrin concentrations during batch adsorption kinetics experiments were determined using the method of Indyk and Filonzi [48], using a surface plasmon resonance technique (SPR) on a Biacore 3000 instrument (Biacore, Uppsala, Sweden). Raw whole milk samples were centrifuged at $4800 \mathrm{~g}$ (Min-Spin, Ependorf, Hamburg, Germany) for 2 minutes to remove fat and filtered using a $5 \mu \mathrm{m}$ filter before serial dilutions (to 2000x) were made in $500 \mathrm{mM}$ HBS-EP buffer (10 mM HEPES, pH 7.4 with 3 mM EDTA and $0.005 \%(\mathrm{v} / \mathrm{v})$ surfactant P20). The running buffer was obtained from Biacore as $150 \mathrm{mM} \mathrm{HBS}$ and $\mathrm{NaCl}$ concentrations were enhanced to $500 \mathrm{mM}$ for sample and standard preparations to reduce non-specific interactions. Lactoferrin concentrations were also measured using a bovine lactoferrin Elisa kit (Bethyl Laboratories) with some modifications as described by Turner et al. [49].

Slurry draining experiments were carried out in a $0.5 \mathrm{~m}$ Perspex tube (70 mm i.d.) with a 44 $\mu \mathrm{m}$ stainless steel filter (mesh 325) (Mounts Wire Industries, Auckland, New Zealand) across one end, fabricated by placing the mesh (75 mm diameter) across the end of the tube, inserting the tube into a tightly fitting funnel and sealing with silicon sealant. A $12 \mathrm{~mm}$ PVC ball valve was attached to the outlet of the funnel. The tube was clamped in a vertical position with the mesh at the bottom and a three-bladed turbine impeller was inserted to a height of $5 \mathrm{~cm}$ above the mesh. Raw milk at $35{ }^{\circ} \mathrm{C}$ was poured in to a height of $35 \mathrm{~cm}$ and swelled, $45.8 \mathrm{~mL}$ of drained media was added (equivalent to $250 \mathrm{~mL}$ media per $15 \mathrm{~L}$ of milk). After about 30 seconds of mixing, the outlet valve was opened and the height of the milk/media slurry was recorded against time. 


\section{Results and Discussion}

The equilibrium adsorption isotherms for LF on BB and FF media are shown in Figure 2. The maximum static binding equilibrium capacity for LF (MW $77 \mathrm{kDa}$ ) BB media compares well with the manufacturer's claims for dynamic capacity of bovine serum albumin (MW 67 $\mathrm{kDa}$ ) at $12 \mathrm{~cm} / \mathrm{hr}$ loading rate [50]. Similarly, the maximum capacity of the FF media compares well with the manufacturer's claims for human serum albumin (MW $67 \mathrm{kDa}$ ) of $110 \mathrm{mg} / \mathrm{mL}$.

The maximum capacity of the media is very high for standard solutions at high concentration but $\mathrm{Q}_{\mathrm{LF}}{ }^{*}$ is strongly dependent on $\mathrm{C}_{\mathrm{LF}}{ }^{*}$ below $1 \mathrm{mg} / \mathrm{mL}$. Because the concentration of LF in milk (Table 1) is below $1 \mathrm{mg} / \mathrm{mL}$, the media capacity in milk will be much lower than the maximum value shown in Figure 2. It may also be the case that other milk components will adversely affect the binding of LF but we did not investigate this.

Figure 3 shows the LF concentration in milk versus time for a media volume to milk volume ratio, $\Phi$, of 0.01 (equivalent to $150 \mathrm{~mL}$ media in $15 \mathrm{~L}$ milk) for BB media. Clearly, the adsorption is too slow to capture the majority of protein in the time required for individual milkings.

Figure 4 shows the adsorption rates for a range of $\Phi$ values of FF media. The adsorption kinetics are much faster than for BB media (average diameter $155 \mu \mathrm{m}$ ), due to the smaller diameter of FF media particles $(90 \mu \mathrm{m})$. The approach to equilibrium appears to be fast enough to absorb significant amounts of LF within a few minutes. At 45 minutes, the adsorption appears to be at or close to equilibrium.

Rowe et al [1] presented a phenomenological kinetic (the composite nonlinear (CNL)) model for adsorption of proteins on suspended anion exchange media particles. The fit between the model and experimental measurements for bovine serum albumin adsorption was far superior to either the Langmuir [51] or the commonly used solid-film linear [52] kinetic models. Key equations from Rowe et al are reproduced below for the sake of clarity. The equation for the CNL model is: 


$$
\ln \left(1-\frac{q}{q_{k}}\right) \ln \left(\frac{C}{C_{o}}\right)=k t+y(0)\left[1-e^{(-a t)}\right] .
$$

In equation (1), $\mathrm{q}$ is the average solid-phase protein concentration per $\mathrm{mL}$ of media $(\mathrm{mg} / \mathrm{mL}), \mathrm{q}_{\mathrm{k}}$ is a kinetic capacity parameter for the solid phase $(\mathrm{mg} / \mathrm{mL}), \mathrm{C}$ is the average solution-phase protein concentration $(\mathrm{mg} / \mathrm{mL}), \mathrm{C}_{\mathrm{o}}$ is the starting solution-phase protein concentration $(\mathrm{mg} / \mathrm{mL}), \mathrm{k}$ is a rate constant $\left(\mathrm{min}^{-1}\right), \mathrm{y}(0)$ is the zero-time intercept when the term on the left hand side of equation (1) is plotted against time, $\mathrm{t}(\mathrm{min})$, and a is a time constant $\left(\mathrm{min}^{-1}\right)$ which accounts for the approach to a steady-state adsorption regime.

Following the original methodology [1], the parameters $\mathrm{k}$ and $\mathrm{y}(0)$ were determined for LF adsorption on FF media from the linear portion of a plot of the left hand side of equation (1) against $\mathrm{t}$, using experimental values and adjusting $\mathrm{q}_{\mathrm{k}}$ to maximise the linear regression coefficient. At this stage, the time constant, a, was not determined.

Again following the authors [1], differentiation of equation (1) with respect to time gives the adsorption rate for $\mathrm{t}>0$,

$$
\frac{d C}{d t}=-\Phi \frac{d q}{d t}=\frac{[k+a \cdot y(0) \cdot \exp (-a \cdot t)] \cdot C \cdot\left(q_{k}-q\right)}{\left(q_{k}-q\right) \cdot \ln \left(1-\frac{q}{q_{k}}\right)+\left(\frac{1}{\Phi}\right) \cdot C \cdot \ln \left(\frac{C}{C_{o}}\right)}
$$

and the initial adsorption rate is determined by twice differentiating equation (1) with respect to time, giving, at $\mathrm{t}=0$,

$$
\frac{d C}{d t}=-\Phi \frac{d q}{d t}=-a \sqrt{\frac{-\Phi q_{k} y(0) C_{o}}{2}}
$$

Equations (2) and (3) were solved using the differential equation solver function ("rkadapt”) in MathCad ${ }^{\mathrm{TM}}$ (Mathsoft, Cambridge, MA, USA) with the time constant, a, determined by adjusting an initial guess to minimise the sum of squares fit between the model and experimental data. 
The curves in figure 4 show that the fit between the CNL model and experimental observations is very good, accounting for both the initial LF concentration and the media volume to milk volume ratio. Work is currently being undertaken to determine the effects of initial LF concentration and milk volume for a constant volume of FF media (250 mL) on the parameters $\mathrm{k}, \mathrm{a}, \mathrm{y}(0)$ and $\mathrm{q}_{\mathrm{k}}$. If empirical functions for these parameters can be determined across the entire operating range for LF extraction from raw milk, this will allow a priori modelling of the extraction process. If the initial protein concentration is known, extraction times could be adjusted to obtain a specific protein capture \% (set by economic considerations). Conversely, by measuring the protein yield for a known extraction time and milk volume, the initial LF concentration in the milk can be determined, indicating the productivity of a specific animal.

Thus, the model could be used to control the extraction process in the industrial sense, to gather information for farm management, or as a method for gathering experimental data on various aspects of animal productivity in field trials.

From the CNL model, we can predict the extraction \% for a fixed volume of media and a range of milk volumes. Figure 5 shows the predicted extraction \% of lactoferrin for reasonable volume yields of milk per individual animal (10 to $25 \mathrm{~L}$ ), assuming a fixed media volume of $250 \mathrm{~mL}$. For an extraction time of 10 minutes, extraction ranges from 60 to $80 \%$, depending on the volume yield of milk. At 20 minutes extraction is between 75 and $88 \%$. At higher extraction times, $\Phi$ makes only a relatively small difference to the extraction percentage obtained.

At the end of adsorption, the loaded media must be recovered from the milk. When allowed to drain through a mesh in dead-end filtration mode, the retained media quickly builds up as a cake on the mesh and exerts a flow resistance so that the draining rate quickly falls nearly to zero. This drainage rate fall-off is especially severe if the milk/media slurry is allowed drain in an uncontrolled manner initially (e.g. by suddenly opening a valve), presumably because the media particles are driven into, and then plug, the mesh pores. However, if the media can be kept in suspension during drainage by stirring near the mesh surface, mesh 
blockage does not occur and there is no media cake on the mesh to cause flow resistance until the very end of the process.

Figure 6 shows the drain times for FF media at two stirrer rates. At the higher stirring rate, the milk/media slurry drains fast enough to fit within a reasonable timeframe for the process. The effect of the stirrer type and speed on the physical stability of the FF media is still to be determined but will clearly be important. If the FF media breaks up under stirring, a more rigid media may have to be used.

On-farm processing of raw milk need not be restricted to ion exchange chromatography but could be applied to other chromatographic techniques, particularly affinity chromatography. For example, Protein A media could be used to recover immunoglobulins directly from standard or hyperimmune milk or from colostrum. Affinity chromatography might be used to extract recombinant proteins directly from the milk of transgenic animals quickly and at maximum yield and activity.

The trade-offs between target extraction \%’s, processing time, media volume per batch, final activity and yield of the target protein(s), and so on will be subject to economic considerations and will vary widely, depending on the objectives of particular extraction. For instance, on-farm extraction of LF and LP from milk, where the intention is to subsequently pass the milk on for further dairy processing, is a different prospect entirely from extraction of a recombinant protein from transgenic milk, where the exhausted milk is a waste product.

However, the possibility that the milking shed can produce not only bulk milk but also, or even instead, chromatographic media loaded with specific target proteins ready for elution and further purification by a secondary processor, offers exciting possibilities for a range of applications. 


\section{Conclusions}

We have explored some design considerations for the on-farm, batch extraction of proteins directly from raw, untreated milk. Advantages of extracting proteins from individual animals include the minimisation of microbial growth and the potential for batch traceability between individual animals and final product lots.

A demonstration of single-stage stirred tank extraction of bovine lactoferrin onto a cation exchanger shows that processing can be achieved within the timeframe required to milk an individual animal and can result in extraction of up to $80 \%$ of the original protein content of the milk in 10 minutes. No pre-treatment of the milk is required and the temperature of the milk as it is obtained from the cow is ideally suited to the extraction process.

The composite nonlinear kinetic model of Rowe et al [1] can be used to fit the batch adsorption of LF from raw milk by cation exchange chromatography and offers the potential to control batch extraction time to meet specific target extraction levels for given initial protein concentrations. Conversely, the model will allow calculation of initial protein concentrations given extraction time, media volume to milk volume ratio and the final protein adsorption level achieved.

The on-farm extraction of proteins shows promise for both the production of minor, highvalue proteins from conventional milk and for production of recombinant proteins from the milk of transgenic animals. The process is not limited to ion exchange but could be implemented using other chromatographic techniques, such as affinity or reverse-phase chromatography. 


\title{
Symbols Used
}

\author{
a time constant, $\min ^{-1}$ \\ C solution-phase protein concentration, $\mathrm{mg} \mathrm{mL}^{-1}$ \\ $\mathrm{C}_{\mathrm{LF}}$ * solution-phase protein concentration at equilibrium with \\ solid-phase concentration, $\mathrm{Q}_{\mathrm{LF}}{ }^{*}$, $\mathrm{mg} \mathrm{mL}^{-1}$ \\ $\mathrm{C}_{0}$ initial solution-phase protein concentration, $\mathrm{mg} \mathrm{mL}^{-1}$ \\ $\mathrm{k} \quad$ rate constant, $\min ^{-1}$ \\ q solid-phase protein concentration, $\mathrm{mg} \mathrm{mL}^{-1}$ of media \\ $\mathrm{q}_{\mathrm{k}} \quad$ kinetic constant used in the CNL model, $\mathrm{mg} \mathrm{mL}^{-1}$ \\ $\mathrm{Q}_{\mathrm{LF}} *$ solid-phase protein concentration at equilibrium with \\ solution-phase concentration, $\mathrm{C}_{\mathrm{LF}}{ }^{*}, \mathrm{mg} \mathrm{mL}^{-1}$ \\ $y(0)$ zero-intercept for straight line fit of linear portion of equation (1) \\ t time, $\min$
}

\section{Greek}

$\Phi \quad$ chromatography media volume to milk volume ratio

\section{Acknowledgements}

The authors gratefully acknowledge support from Dr Rod Claycomb (Sensortec Ltd, Hamilton, NZ), Dr Norm Thomson (Dexcel Ltd, Hamilton, NZ) and Dr Tony Mathews (ICbio Ltd, Auckland, NZ). Amita Chand is the recipient of a NZ Government Enterprise Doctoral Scholarship from Tech New Zealand. 


\section{References}

1. Rowe, G.E., A. Maragaritis, Q. Lan, A.S. Bassi, and J.-X. Zhu, Biotechnology and Bioengineering, 1999. 65(6): 613-621.

2. $\quad$ Yoshida, T., Journal of Dairy Science, 1991. 74: 1439-1444.

3. Denman, J., M. Hayes, C. O'Day, T. Edmunds, C. Bartlett, S. Hirani, K.M. Ebert, K. Gordon, and J.M. McPherson, Bio/Technology, 1991. 9(9): 839-843.

4. Wolf, E., P.M. Jehle, M.M. Weber, H. Sauerwein, A. Daxenberger, B.H. Breier, U. Besenfelder, L. Frenyo, and G. Brem, Endocrinology, 1997. 138(1): 307-313.

5. $\quad$ Degener, A., M. Belew, and W.H. Velander, Journal of Chromatography A, 1998. 799: 125-137.

6. Pollock, D.P., J.P. Kutzko, E. Birck-Wilson, J.L. Williams, Y. Echelard, and H.M. Meade, Journal of Immunological Methods, 1999. 231(1-2): 147-157.

7. Wright, G. and J. Noble, in Bioseparation and Bioprocessing, G. Subramanian, Editor, Wiley-VCH: NY. p. 67-79, 1999.

8. Ko, J.H., C.-S. Lee, K.H. Kim, M.-G. Pang, J.S. Koo, N. Fang, D.-B. Koo, K.B. Oh, W.-S. Youn, G.D. Zheng, J.S. Park, S.J. Kim, Y.-M. Han, I.Y. Choi, J. Lim, S.T. Shin, S.W. Jin, K.-K. Lee, and O.J. Yoo, Transgenic Research, 2000. 9(3): 215-222.

9. Andrews, A.T., D.P. Harris, G. Wright, D.L. Pyle, and J.A. Asenjo, Biotechnology Letters, 2000. 22(17): 1349-1353.

10. Fulton, S. presented at Recovery of Biological Products 10. Cancun, Mexico: American Chemical Society, 2001.

11. Baruah, G.L., D. Couto, and G. Belfort, Biotechnology Progress, 2003. 19: 15331540.

12. Lindsay, M., G.-C. Gil, A. Cadiz, W.H. Velander, C. Zhang, and K.E. Van Cott, Journal of Chromatography A, 2004. 1026(1-2): 149-157.

13. Nikolov, Z.L. and S.L. Woodard, Current Opinion in Biotechnology, 2004. 15(5): 479-486.

14. Parker, M.H., E. Birck-Wilson, G. Allard, N. Masiello, M. Day, K.P. Murphy, V. Paragas, S. Silver, and M.D. Moody, Protein Expression and Purification, 2004. 38(2): 177-183.

15. Capezio, L., D. Romanini, G.A. Pico, and B. Nerli, Journal of Chromatography B, 2005. 819(1): 25-31.

16. Morison, K.R. and L. Joyce, Food New Zealand, 2005: 22-30.

17. Lonnerdal, B. and J. Carlsson, FEBS Letters, 1977. 75(1): 89-92.

18. Humphrey, R.S. and L.J. Newsome, New Zealand Journal of Diary Science and Technology, 1984. 19: 197-204.

19. Andrews, A.T., M.D. Taylor, and A.J. Owen, Journal of Chromatography, 1985. 348: 177-185.

20. Chaplin, L.C., Journal of Chromatography, 1986. 363(2): 329-35.

21. Al-Mashikhi, S.A. and S. Nakai, Journal of Dairy Science, 1987. 70(12): 2486-92.

22. Al-Mashikhi, S.A. and E. Li-Chan, Journal of Dairy Science, 1988. 71: 1747-1755.

23. Yoshida, S., Journal of Dairy Science, 1988. 71(1): 1-9.

24. Donnelly, W.J., Journal of the Society of Dairy Technology, 1991. 44(3): 67-72.

25. Visser, S., C.J. Slangen, and H.S. Rollema, Journal of Chromatography, 1991. 548(1-2): 361-70. 
26. de Frutos, M., A. Cifuentes, L. Amigo, M. Ramos, and J.C. Diez-Masa, Z Lebensm Unters Forsch, 1992. 195(4): 326-31.

27. Morr, C.V. and E.Y.W. Ha, Critical Reviews in Food Science and Nutrition, 1993. 33(6): 431-476.

28. Konecny, P., R.J. Brown, and W.H. Scouten, Journal of Chromatography A, 1994. 673(1): 45-53.

29. Francis, G.L. and G.O. Regester, Journal of Dairy Science, 1995. 78: 1209-1218.

30. Torre, M. and M.E. Cohen, Journal of Chromatography A, 1996. 729: 99-111.

31. $\quad$ Felipe, X. and A.J.R. Law, Journal of Dairy Research, 1997. 64: 459-464.

32. Etzel, M.R., A.D. Liten, and P.M. Moore. presented at 2nd International Conference on Expanded Bed Adsorption. Whistler, 1998.

33. Geberding, I.J. and C.H. Byers, Journal of Chromatography A, 1998. 808: 141-151.

34. Hahn, R., P.M. Schulz, C. Schaupp, and A. Jungbauer, Journal of Chromatography A, 1998. 795(2): 277-287.

35. Noppe, W., P. Haezebrouck, I. Hanssens, and M. De Ouyper, Bioseparation, 1999. 8(1/5): 153-158.

36. Elgar, D.F., C.S. Norris, J.S. Ayers, M. Pritchard, D.E. Otter, and K.P. Palmano, Journal of Chromatography A, 2000. 878(2): 183-96.

37. $\mathrm{Xu}, \mathrm{Y} ., \mathrm{R}$. Sleigh, J. Hourigan, and R. Johnson, Process Biochemistry, 2000. 36 : 393-399.

38. Ye, X., S. Yoshida, and T.B. Ng, The International Journal of Biochemistry \& Cell Biology, 2000. 32(11-12): 1143-1150.

39. Doultani, S., K.N. Turhan, and M.R. Etzel, Process Biochemistry, 2004. 39(11): 1737-1743.

40. Ladisch, M.R., Bioseparations Engineering: Principles, Practice and Economics, New York: John Wiley \& Sons, 2001.

41. Harrison, R.G., P.W. Todd, S.R. Rudge, and D. Petrides, Bioseparations Science and Engineering. Topics in Chemical Engineering: A Series of Textbooks and Monographs, ed. K.E. Gubbins, Oxford: Oxford University Press, 2003.

42. $\quad$ Nuyens, J.H. and H.H. Van Veen, US Patent 6,183,803, 1999.

43. Claycomb, R.W., World Intellectual Property Organization Patent WO 2004056193, 2004.

44. Bylund, G. and TetraPak, Dairy Processing Handbook. 2nd ed, Lund, Sweden: Tetra Pak Processing Systems AB, 2003.

45. Fee, C.J. and A. Chand, Separation \& Purification Technology, 2005 (Special Issue: "Separation and Purification Processes in Food Industry for Value-Adding Production"): in press.

46. http://www.cfsan.fda.gov/ dms/opa-fcn.html, Accessed 04/04/05, 2004.

47. Woolford, M., K. Davis, J. Jago, and R.W. Claycomb. presented at Proceedings of the National Milk Quality Conference. Hamilton, New Zealand. p. 37-39., 2003.

48. Indyk, H.E. and E.L. Filonzi, International Dairy Journal, 2005. in press.

49. Turner, S.-A., J.H. Williamson, N.A. Thomson, J.R. Roche, and E.S. Kolver, Proceedings of the New Zealand Society of Animal Production, 2003. 63: 87-90.

50. http://www.chromatography.amershambiosciences.com/, Accessed 04/04/05, 2005.

51. Skidmore, G.L., B.J. Horstmann, and H.A. Chase, Journal of Chromatography, 1990. 498: 113-128.

52. Tien, C., Adsorption calculations and modelling, Boston: Butterworth-Heinemann, 1994. 


\section{Tables}

Table 1. Typical concentrations of whey proteins and their isoelectric points [16].

\begin{tabular}{lcc}
\hline Protein & $\begin{array}{c}\text { Approx. Concentration } \\
\text { in Whey (\%) }\end{array}$ & Isoelectric point \\
\hline$\beta$-Lactoglobulin & 0.30 & $5.35-5.49$ \\
$\alpha$-Lactalbumin & 0.07 & $4.2-4.5$ \\
Immunoglobulins & 0.06 & $5.5-8.3$ \\
Bovine serum albumin & 0.03 & 5.13 \\
Protease-peptones & 0.14 & $3.3-3.7$ \\
Lactoferrin & 0.003 & $7.8-8.0$ \\
Lactoperoxidase & 0.002 & $9.2-9.9$ \\
\hline
\end{tabular}




\section{Figure Legends}

Figure 1. The effect of column diameter on design parameters.

Figure 2. Equilibrium isotherms for lactoferrin on SP Sepharose Big Bead and SP Sepharose FF media, measured in a standard solution. The lines fitted through the points are from the Langmuir isotherm.

Figure 3. Lactoferrin concentration in milk during batch extraction with BB media as a function of time, for three values of $\Phi$.

Figure 4. Lactoferrin concentration in milk during batch extraction with FF media as a function of time. Lines were calculated from the CNL model, using the following parameters: at $\Phi=0.010, \mathrm{a}=0.29, \mathrm{q}_{\mathrm{k}}=62.7, \mathrm{y}(0)=-0.21, \mathrm{k}=0.0731$; at $\Phi=0.013$, $\mathrm{a}=0.22, \mathrm{q}_{\mathrm{k}}=40.7, \mathrm{y}(0)=-0.51, \mathrm{k}=0.1516 ; \Phi=0.024, \mathrm{a}=0.5, \mathrm{q}_{\mathrm{k}}=17.7$, $\mathrm{y}(0)=-0.32, \mathrm{k}=0.3362$.)

Figure 5. Amount of lactoferrin extracted at various times as a function of $\Phi$, expressed as milk volume corresponding to a fixed media volume of $250 \mathrm{~mL}$.

Figure 6. Milk/media slurry draining rate with stirring. 


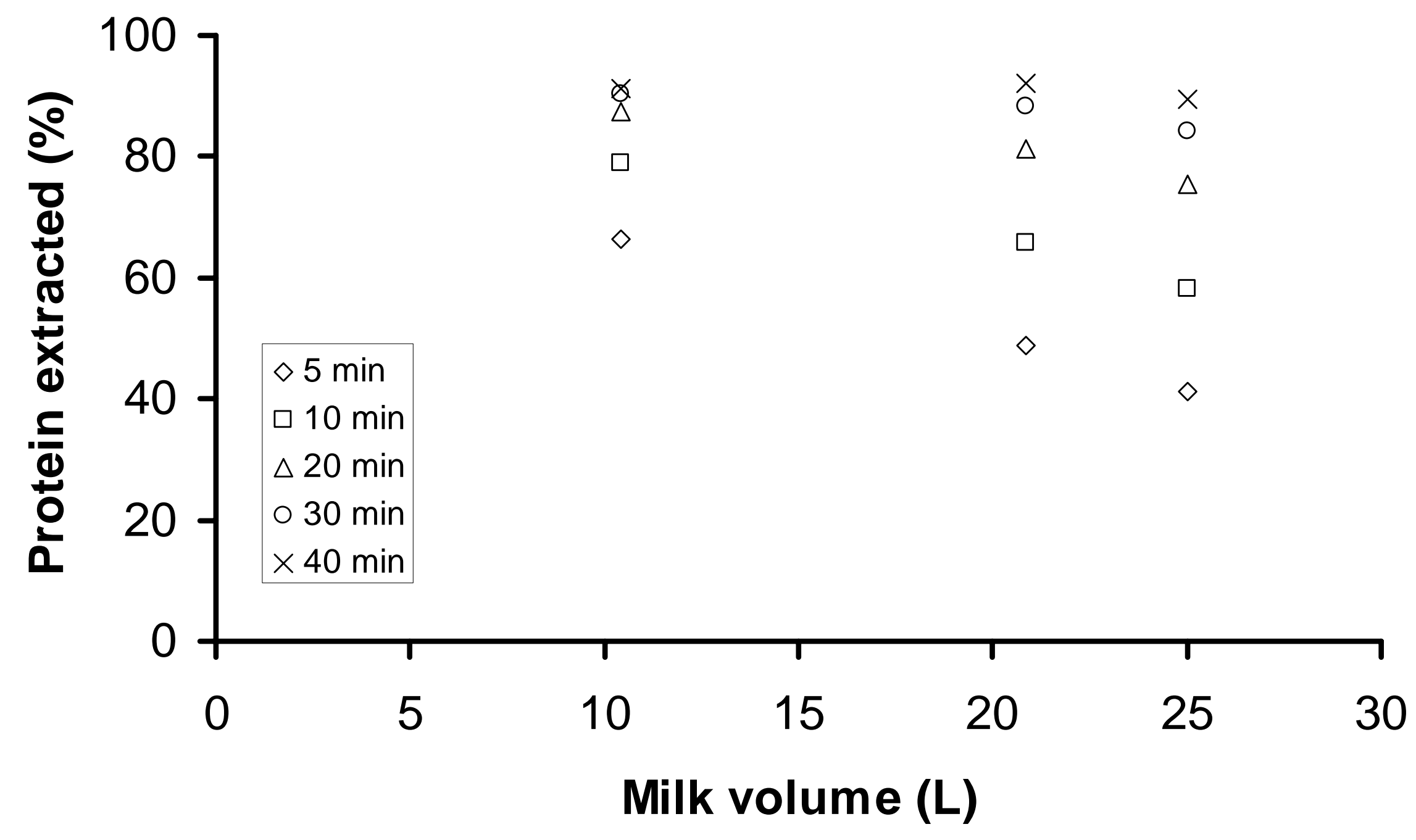




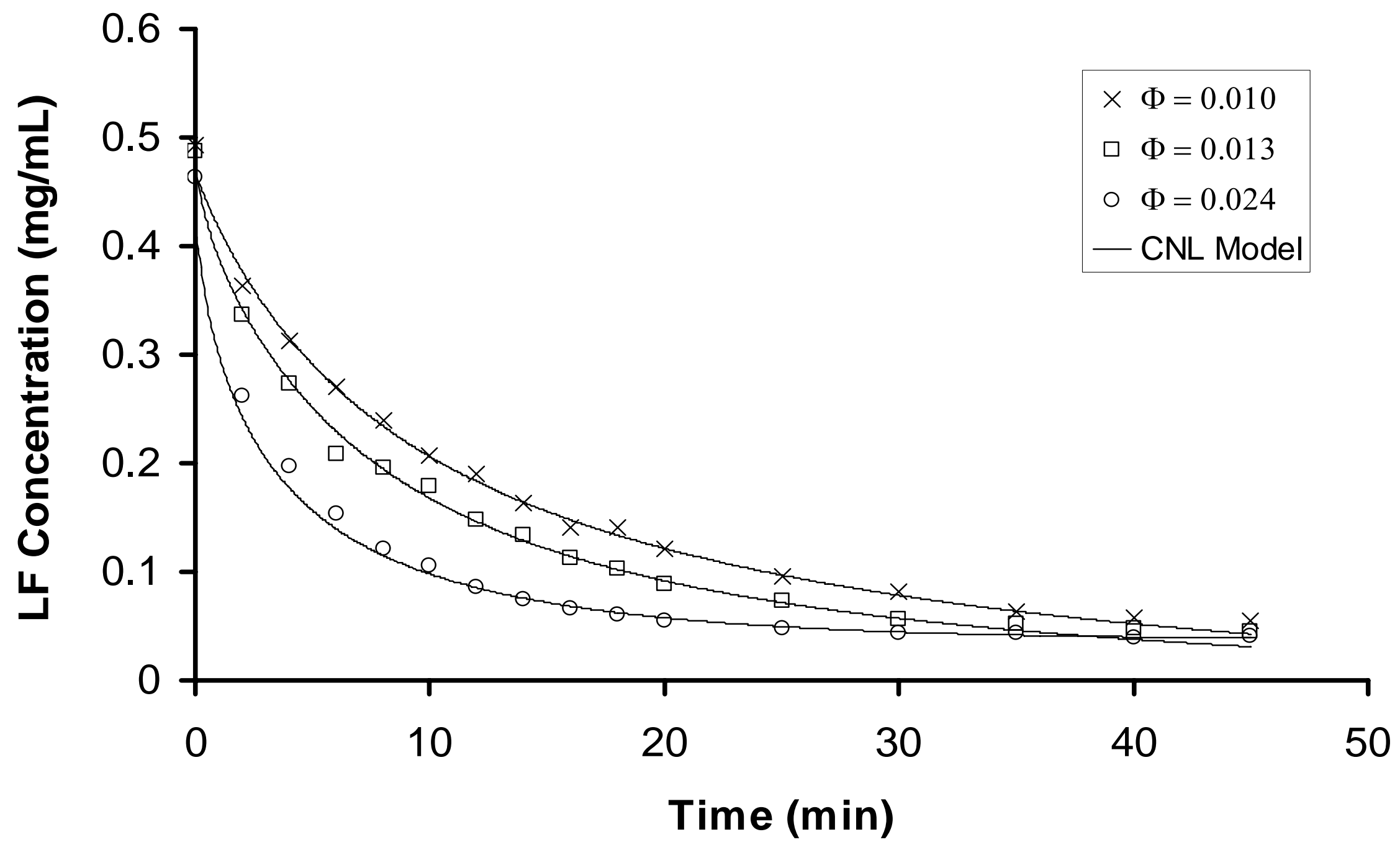




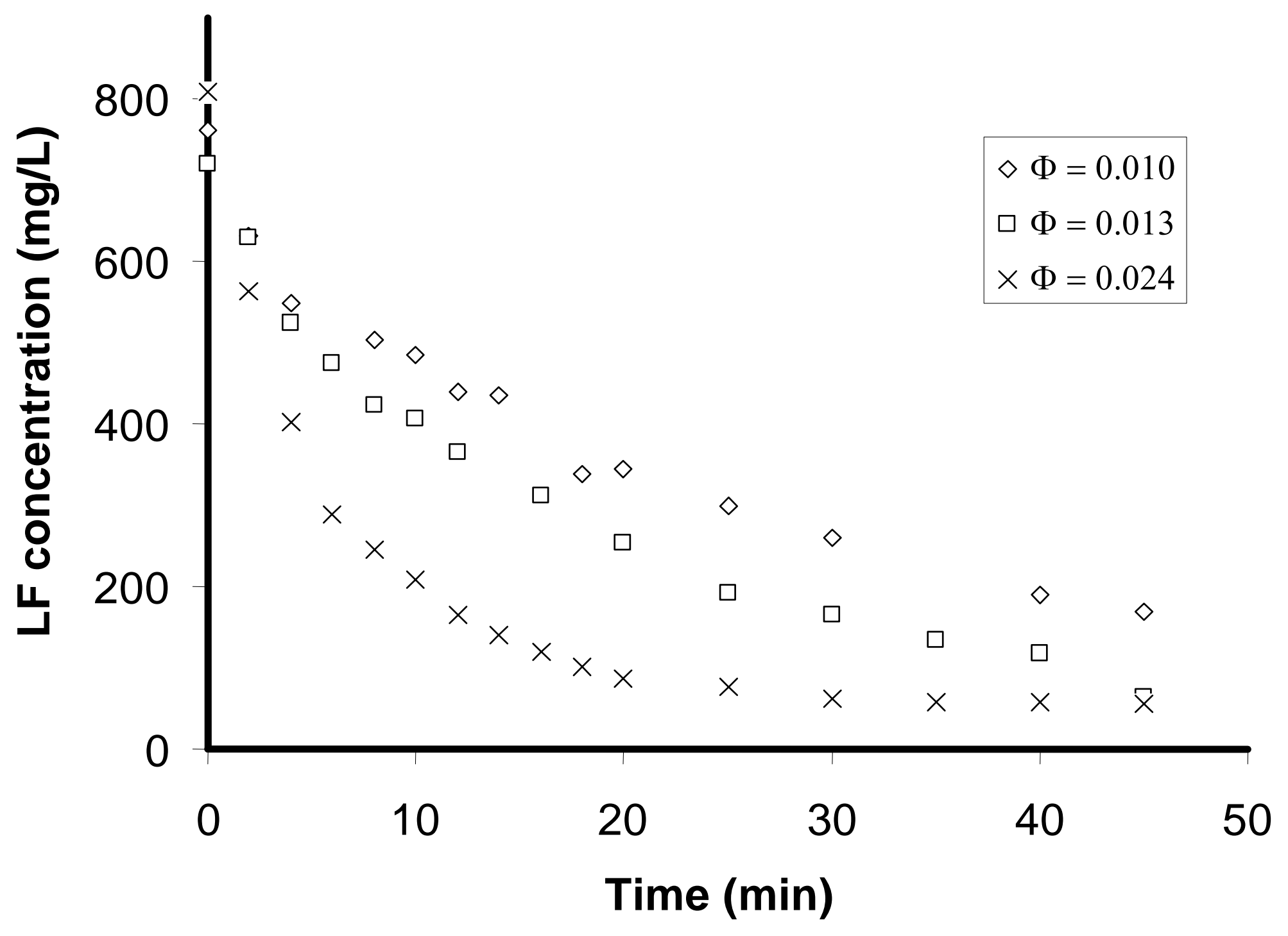




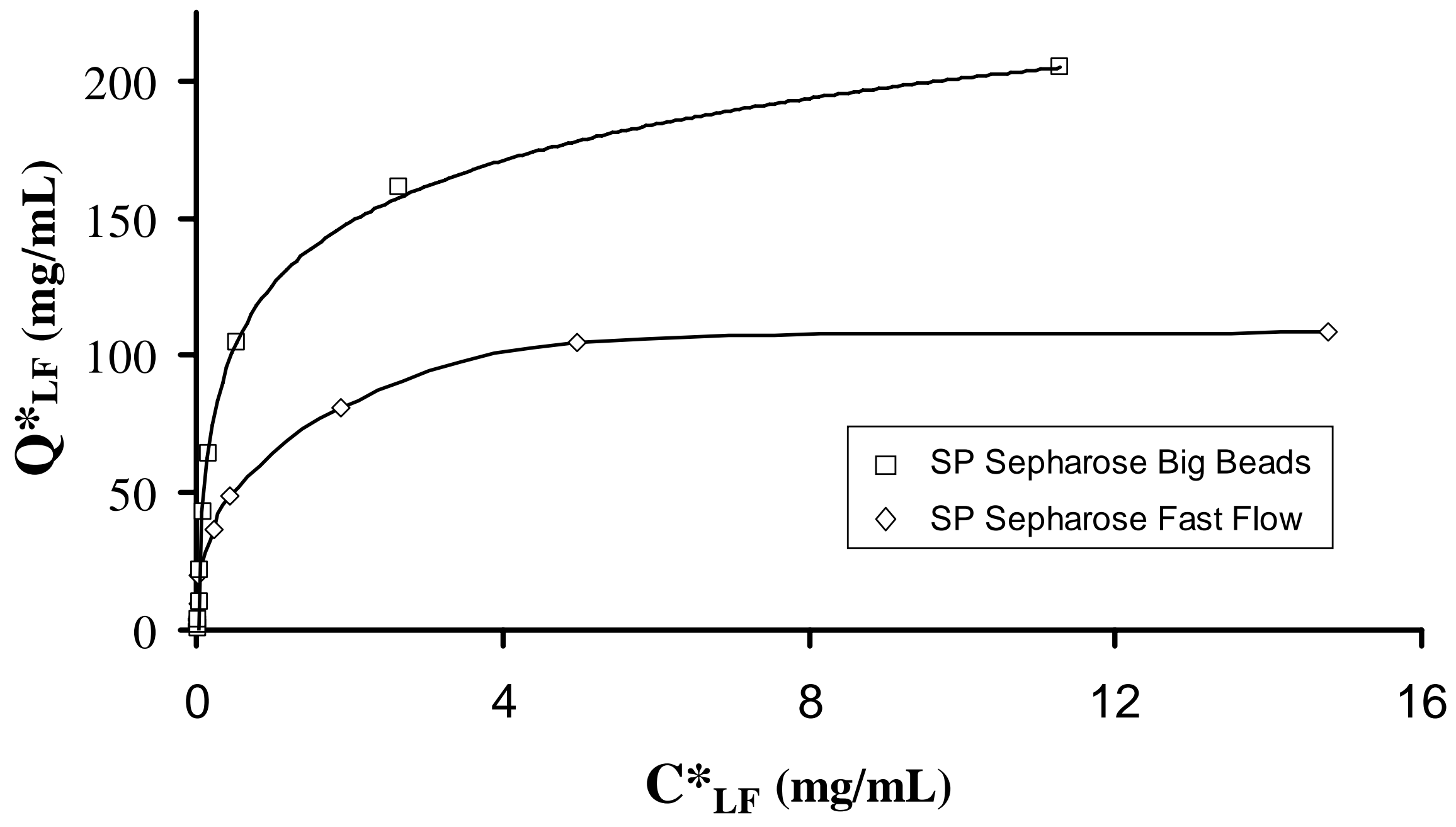




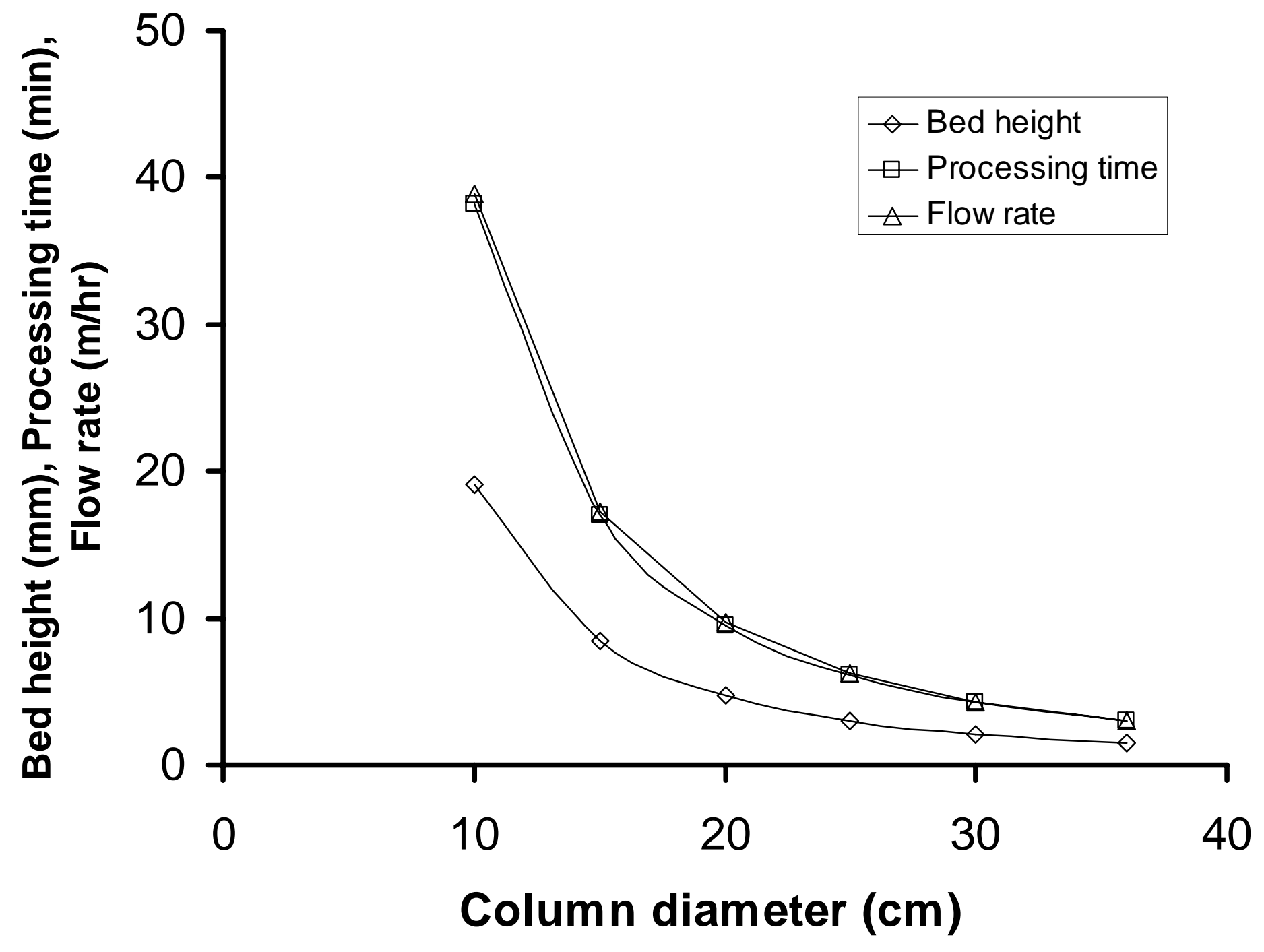




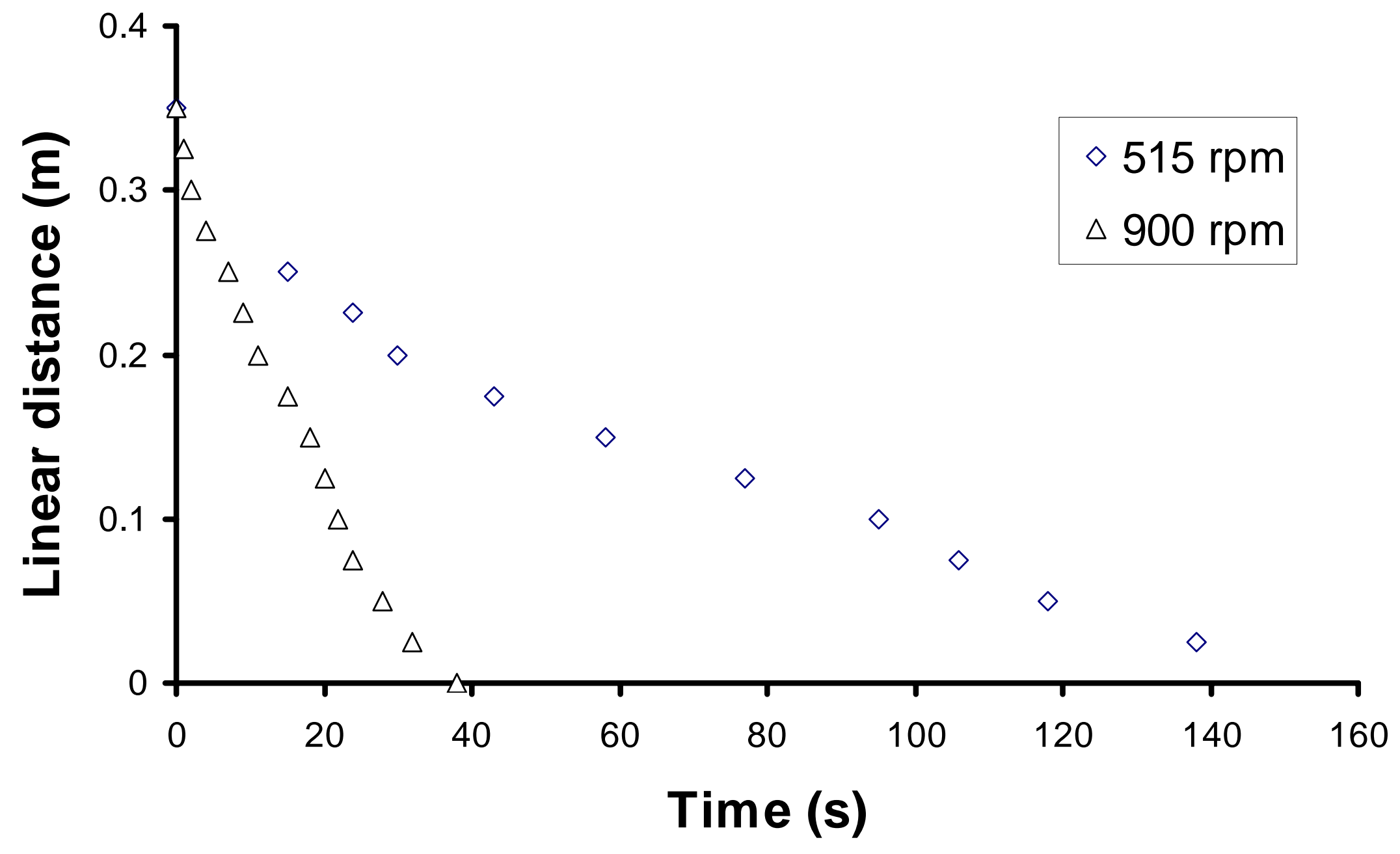

